\title{
Editorial
}

\section{Uso racional del Agua para un desarrollo económico y social sostenible}

El crecimiento acelerado de la población ha provocado presiones adicionales sobre los recursos naturales, impactando negativamente su calidad y comprometiendo seriamente la sustentabilidad de los mismos. Es indudable el aumento de la demanda de agua dulce para realizar las actividades antrópicas, generando sobreexplotación del recurso hídrico en las fuentes de abastecimiento. Por lo tanto, cada vez se hace más relevante el manejo integrado del recurso hídrico a nivel de cuenca, teniendo en cuenta, las características morfológicas de la misma, el cambio climático y la dinámica del crecimiento poblacional y económico de sus moradores.

Según el reporte número tres (3) de Naciones Unidas titulado "El agua en un mundo cambiante (2009)", el manejo apropiado del recurso hídrico es esencial para el desarrollo económico y social, así mismo, ayuda a mejorar indicadores como la equidad, servicios ambientales y reducir la pobreza; todos relevantes para lograr los objetivos de desarrollo del milenio.

En algunos lugares del mundo ya empieza a escasear el agua dulce y, los acuíferos están siendo explotados a tasas superiores a la de su recarga o recuperación. Sandra L Postel en el año 2000 manifestó que en todo el planeta se ven numerosos indicios de que el efecto antrópico sobre el agua supera los niveles sostenibles debido al agotamiento del recurso hídrico y su nivel de contaminación. En ese mismo sentido, En el reporte número tres (3) del desarrollo mundial del Agua de las Naciones Unidas (2009) se manifiesta que la tasa de crecimiento poblacional a nivel global se estima en 80 millones de personal por año, lo que implicará un incremento en la demanda de agua alrededor de 64 billones de metros cúbicos por año.

Basado en lo anterior, el presente volumen especial de la Revista Ingeniería y Región de la Universidad Surcolombiana, publica los mejores trabajos presentados en el Congreso Internacional de Uso Racional del agua USRA e Ingeniería Agrícola, el cual tuvo como objetivo divulgar a la comunidad académica y científica avances de investigación relacionados y aplicados a la agricultura y agroindustria en el manejo eficiente del agua a nivel nacional e internacional, como una respuesta clara para lograr los objetivos de desarrollo del milenio, abordando áreas temáticas, tales como: biosistemas, recurso agua-suelo, agricultura de precisión, uso de sistemas de Información Geográficos, procesos hidrológicos y agroindustriales, apoyadas de la mecanización agrícola y construcciones rurales.

\section{Marlio Bedoya Cardoso}

D.Sc. en Economía Agrícola

Profesor de Ingeniería Agrícola, Área adecuación de tierras

Universidad Surcolombiana 